\title{
The Efficiency Index (EFFi), based on volumetric capnography, may allow for simple diagnosis and grading of COPD
}

This article was published in the following Dove Press journal: International Journal of COPD

\section{Linnea Jarenbäck' \\ Ellen Tufvesson' \\ Jaro Ankerst ${ }^{\prime}$ \\ Leif Bjermer' \\ Björn Jonson ${ }^{2}$}

'Respiratory Medicine and Allergology, Department of Clinical Sciences, Skåne University Hospital, Lund University, Lund, Sweden; ${ }^{2}$ Clinical Physiology, Department of Clinical Sciences, Skåne University Hospital, Lund University, Lund, Sweden
Correspondence: Linnea Jarenbäck Respiratory Medicine and Allergology, Department of Clinical Sciences, Skåne University Hospital, Lund University, BMC, DI 2, 22I 84 Lund, Sweden Tel +46 46 I75 277

Email linnea.jarenback@med.lu.se
Background: Spirometry, the main tool for diagnosis and follow-up of COPD, incompletely describes the disease. Based on volumetric capnography (VCap), an index was developed for the diagnosis and grading of COPD, aimed as a complement or alternative to spirometry.

Methods: Nine non-smokers, 10 smokers/former smokers without COPD and 54 smokers/ former smokers with COPD were included in the study. Multiple breath washout of $\mathrm{N}_{2}$ and VCap were studied with Exhalyzer D during tidal breathing. VCap was based on signals for flow rate and $\mathrm{CO}_{2}$ and was recorded during one breath preceding $\mathrm{N}_{2}$ washout. Efficiency Index (EFFi) is the quotient between exhaled $\mathrm{CO}_{2}$ volume and the hypothetical $\mathrm{CO}_{2}$ volume exhaled from a completely homogeneous lung over a volume interval equal to $15 \%$ of predicted total lung capacity.

Results: EFFi increased with increased Global initiative for chronic Obstructive Lung Disease (GOLD) stage and the majority of subjects in GOLD 2 and all subjects in GOLD 3 and 4 could be diagnosed as having COPD using the lower $95 \%$ confidence interval of the healthy group. EFFi also correlated with $\mathrm{N}_{2}$ washout $(\mathrm{r}=-0.73 ; p<0.001)$, forced expiratory volume in 1 second $(\mathrm{r}=0.70 ; p<0.001)$ and diffusion capacity for carbon oxide $(\mathrm{r}=0.69 ; p<0.001)$.

Conclusion: EFFi measures efficiency of tidal $\mathrm{CO}_{2}$ elimination that is limited by inhomogeneity of peripheral lung function. EFFi allows diagnosis and grading of COPD and, together with $\mathrm{FEV}_{1}$, may explain limitation of physical performance. EFFi offers a simple, effortless and costeffective complement to spirometry and might serve as an alternative in certain situations.

Keywords: chronic obstructive pulmonary disease, volumetric capnography, carbon dioxide, single breath

\section{Introduction}

Spirometry is the main diagnostic test for COPD and other obstructive diseases. ${ }^{1,2}$ COPD commences with bronchiolitis and centrilobular emphysema for which spirometry has limited sensitivity and, thus, provides incomplete information about physiological aberrations in COPD. ${ }^{2-5}$ Additionally, spirometry requires proper patient collaboration and can, therefore, be problematic to perform in children and mentally/ physically incapable subjects. Diagnoses may therefore be delayed for years, leading to increased burden on patients and society. ${ }^{6,7}$ Inhomogeneity of pathology reduces diffusion capacity of carbon monoxide over the lung $\left(\mathrm{D}_{\mathrm{L}, \mathrm{CO}}\right)$ and retards washout of nitrogen in the multiple breath washout of nitrogen $\left(\mathrm{MBW} \mathrm{N}_{2}\right)$. These tests require complex equipment and are demanding with respect to patient cooperation. In contrast, volumetric capnography (VCap) requires just a few tidal breaths through a pneumotachograph and $\mathrm{CO}_{2}$ analyzer followed by simple computer analysis, leading to a 
more facilitated method of obtaining and analyzing data. In COPD, the shape of the curve from a single breath test for $\mathrm{CO}_{2}\left(\mathrm{SBT} \mathrm{CO}_{2}\right.$ ) differs from that of a healthy subject by a slower rise of $\mathrm{CO}_{2}$ towards an alveolar plateau that, furthermore, has a higher slope. ${ }^{8-11}$

Our objectives were to obtain an index of efficiency of tidal ventilation with respect to $\mathrm{CO}_{2}$ exchange (Efficiency Index, EFFi) and to test the hypothesis that EFFi may be used for diagnostics and grading of COPD. To do this, we modified a concept originally proposed by Fletcher and Jonson and applied in healthy subjects by Åström et al, ${ }^{12}$ so that all relevant information in the $\mathrm{SBT} \mathrm{CO}_{2}$ was taken into account, while non-relevant information was excluded. ${ }^{13}$

\section{Materials and methods}

Lung function measurements have been previously described in the "Materials and methods" section of the study by Jarenbäck et al. ${ }^{14}$ Subjects were recruited from a research cohort and from an existing pool of patients attending our research clinic. Exclusion criteria were cardiorespiratory disease other than COPD, including respiratory tract infection during the last 3 weeks and any history of asthma. Study subjects were instructed to refrain from smoking, intake of caffeine and high nitric containing food 2 hours before visiting the clinic. They performed spirometry, $\mathrm{D}_{\mathrm{L}, \mathrm{CO}}$ and $\mathrm{MBW} \mathrm{N}_{2}$ (including VCap) in the given order. All lung function measurements were performed without bronchodilator (except for in very severe subjects who could not refrain from their standard medications due to dyspnea). Ethical permission was given by the Regional Ethical Board in Lund (431/2008), and written informed consent was obtained from each subject. This study followed the guidelines set in the Declaration of Helsinki.

Nine non-smokers, 10 smokers/former smokers without COPD and 54 smokers/former smokers with COPD (Global initiative for chronic Obstructive Lung Disease [GOLD] $1-4)^{1}$ were included. All smokers and former smokers had $>10$ pack years. For spirometry and for $\mathrm{D}_{\mathrm{L}, \mathrm{CO}}$, Master Screen BODY and Master Screen PFT (Erich Jaeger GmbH, Würzburg, Germany) were used, respectively. Reference values for spirometry were defined by Crapo et $\mathrm{al}^{15}$ and for $\mathrm{D}_{\mathrm{L}, \mathrm{CO}}$ by Quanjer et al. ${ }^{16}$

MBW $\mathrm{N}_{2}$ and VCap were studied with Exhalyzer D (Eco Medics, Dürnten, Switzerland). Tidal breaths, 1 L deep, were taken under guidance from a computer screen (Spiroware, Eco Medics). Ventilation heterogeneity in the acinar airways $\left(\mathrm{S}_{\text {acin }}\right)$ that expresses inhomogeneity of the acinar airways is then calculated. ${ }^{17}$ Exhalyzer D uses a mainstream capnograph and an ultrasound flow meter connected to the subject via a mouthpiece and an anti-microbial filter (Electrostatic Filter; GVS Filter Technology, Zola Predosa, Italy). VCap was based on signals for flow rate and fraction of expired $\mathrm{CO}_{2}\left(\mathrm{~F}_{\mathrm{E}} \mathrm{CO}_{2}\right)$ during the $\mathrm{MBW} \mathrm{N}_{2}$. From one breath, before $\mathrm{N}_{2}$ washout with pure oxygen was started, flow and $\mathrm{CO}_{2}$ signals were sampled at a rate of 200 per second and transferred to Microsoft Excel for analyses of the SBT $\mathrm{CO}_{2}$ (Figure 1). The analyses started after expiration of pure airway dead space, which was when $\mathrm{F}_{\mathrm{E}} \mathrm{CO}_{2}$ reached 0.002 and continued over the "analyzed volume" $\left(\mathrm{V}_{\mathrm{AN}}\right)$ which was standardized to $15 \%$ of predicted total lung capacity (TLC). For breaths not covering the whole $\mathrm{V}_{\mathrm{AN}}$, the alveolar plateau was extrapolated as in previous studies. ${ }^{8,18}$ The volume of $\mathrm{CO}_{2}$ exhaled over $\mathrm{V}_{\mathrm{AN}}$ equals area "A". The hypothetical volume of $\mathrm{CO}_{2}$ exhaled from a lung with a completely homogenous function would correspond to the rectangular area $(A+B)$. EFFi was calculated as:

$$
\mathrm{EFFi}=\mathrm{A} /(\mathrm{A}+\mathrm{B})
$$

EFFi represents the ratio between eliminated $\mathrm{CO}_{2}$ over the volume eliminated from a theoretical "ideal" lung and expresses the efficiency of the breath in elimination of $\mathrm{CO}_{2}$.

\section{Statistics}

Statistical analyses were performed in SPSS version 23 for Windows (IBM Corporation, Armonk, NY, USA). Differences between groups were analyzed using the Kruskal-Wallis

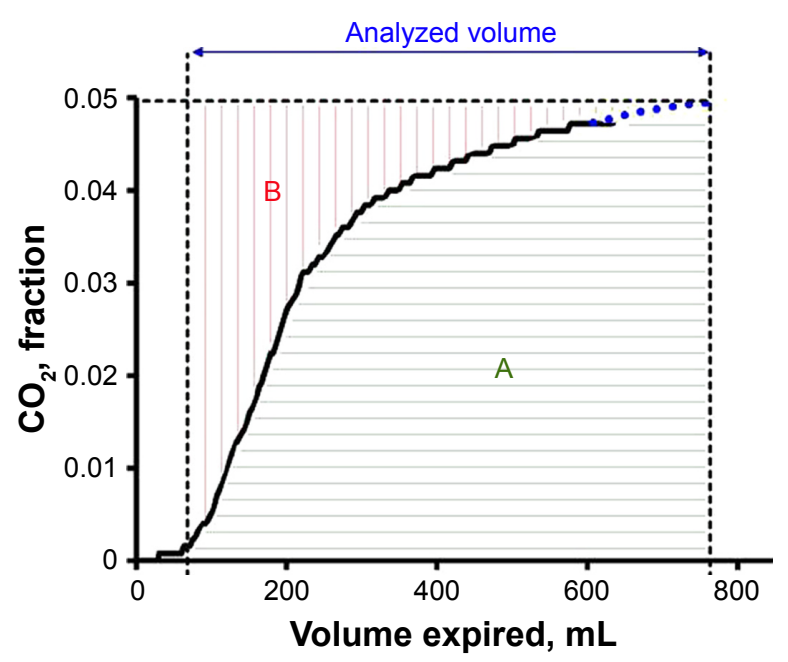

Figure I Single breath test curve for $\mathrm{CO}_{2}$ for calculations of EFFi. Notes: Analyzed volume starts when the $\mathrm{CO}_{2}$ fraction reaches 0.002 and continues to $15 \%$ of predicted TLC. For breaths not covering $15 \%$ of TLC, the alveolar plateau was extrapolated. EFFi was calculated as the quotient between the volume of $\mathrm{CO}_{2}$ exhaled, area $\mathrm{A}$, and the hypothetical volume of $\mathrm{CO}_{2}$ exhaled from a completely homogenous lung, area $(A+B)$.

Abbreviations: EFFi, Efficiency Index; TLC, total lung capacity. 
test with Dunn's post hoc test to compare all groups to each other. Correlations were performed using Spearman's correlation test. All correlations were checked graphically to confirm association. Categorical data between groups were analyzed using the Chi-square test. A value of $p<0.05$ was considered significant. Table data are presented as median with interquartile range. Data in graphs are presented as individual dots with median.

\section{Results}

The different groups were similar in age and height, but lung physiology data showed deterioration with increasing disease severity (Table 1). Figure 2 illustrates $\mathrm{SBT} \mathrm{CO}_{2}$ for the subjects with median EFFi in each group. The curves were normalized so that the volume axis covered $0-100 \%$ of $\mathrm{V}_{\mathrm{AN}}$, while the $\mathrm{CO}_{2}$ axis covered the range from 0 to $100 \%$ of the value at the end of $\mathrm{V}_{\mathrm{AN}}$.

The distribution of EFFi in the different groups is illustrated in Figure 3A. The majority of subjects in GOLD 2 and all subjects in GOLD 3 and 4 showed EFFi below the 95\% confidence interval of healthy subjects. Similar findings were observed for $\mathrm{D}_{\mathrm{L}, \mathrm{CO}}$ and $\mathrm{S}_{\text {acin }}$ (Figure $3 \mathrm{~B}$ and $\mathrm{C}$, respectively).

EFFi correlated with forced expiratory volume in 1 second $\left(\mathrm{FEV}_{1}\right)(\mathrm{r}=0.70 ; p<0.001$; Figure $4 \mathrm{~A}), \mathrm{FEV}_{1} /$ forced vital capacity $\left(\mathrm{r}=0.58 ; p<0.001 ;\right.$ Figure 4B), $\mathrm{D}_{\mathrm{L}, \mathrm{CO}}(\mathrm{r}=0.69 ; p<0.001$; Figure $4 \mathrm{C})$ and $\mathrm{S}_{\text {acin }}(\mathrm{r}=-0.73 ; p<0.001$; Figure 4D).

\section{Discussion}

We found that by analyzing EFFi from a SBT $\mathrm{CO}_{2}$ curve, information about lung pathology could be accessed. This may be used as a simple, inexpensive way to identify subjects with COPD or as a complement to spirometry.
Along a principle related to that used for calculation of EFFi, Åström et al calculated a dead space volume based on information limited to Phase II. In that case, the information related to the high slope of the alveolar plateau in COPD is then ignored. ${ }^{12}$ Our goal was to include all relevant information in the SBT $\mathrm{CO}_{2}$ curve, ie, Phase II and III. Initial fraction of $\mathrm{V}_{\mathrm{AN}}$ contained little $\mathrm{CO}_{2}$ and contributed to low efficiency, while later fractions with higher $\mathrm{CO}_{2}$ content were more efficient. Accordingly, $\mathrm{V}_{\mathrm{AN}}$ must be standardized to avoid influencing EFFi by the volume range of analysis. Tidal volume depends on several factors and is a confounding, non-relevant factor. To compare subjects with different lung size, it was reasoned that predicted TLC is a proper parameter for standardization of $\mathrm{V}_{\mathrm{AN}} \cdot \mathrm{V}_{\mathrm{AN}}$ was set to $15 \%$ of predicted value for TLC, in line with previous studies..$^{8,18}$ Accordingly, $\mathrm{V}_{\mathrm{AN}}$ commenced when $\mathrm{CO}_{2}$ fraction in expired air became significant and ended after expiration of a further $15 \%$ of predicted TLC. When needed, the alveolar plateau was extrapolated to the end point of $\mathrm{V}_{\mathrm{AN}} \cdot{ }^{8,18}$ Future studies based on completely spontaneous ventilation and a lower tidal volume may show if an alternative definition of $\mathrm{V}_{\mathrm{AN}}$ might be favorable.

Area A, as shown in Figure 1, represents the expired $\mathrm{CO}_{2}$ volume while area $(\mathrm{A}+\mathrm{B})$ reflects the theoretical volume of $\mathrm{CO}_{2}$ exhaled from an ideal homogenous lung. Accordingly, $\mathrm{A} /(\mathrm{A}+\mathrm{B})$, ie, EFFi, is an index of the efficiency of the lung with respect to $\mathrm{CO}_{2}$ elimination. EFFi is considered easier to comprehend than any parameter related to alveolar dead space. Being dimensionless, EFFi is independent on the level of $\mathrm{CO}_{2}$ in alveolar gas, on calibration of the $\mathrm{CO}_{2}$ meter and in which unit $\mathrm{CO}_{2}$ content is expressed. The normalization of both expired volume and fraction of $\mathrm{CO}_{2}$ that is inherent in EFFi lends itself to a graphical presentation that facilitates

Table I Patient demographics and characteristics

\begin{tabular}{|c|c|c|c|c|c|c|c|}
\hline & $\begin{array}{l}\text { Never } \\
\text { smokers }(n=9)\end{array}$ & $\begin{array}{l}\text { Smoking } \\
\text { controls }(n=10)\end{array}$ & $\begin{array}{l}\text { GOLD I } \\
(n=8)\end{array}$ & $\begin{array}{l}\text { GOLD } 2 \\
(n=22)\end{array}$ & $\begin{array}{l}\text { GOLD } 3 \\
(n=14)\end{array}$ & $\begin{array}{l}\text { GOLD } 4 \\
(n=10)\end{array}$ & $p$-value \\
\hline Gender (male/female) & $6 / 3$ & $7 / 3$ & $5 / 3$ & $12 / 10$ & $9 / 5$ & $2 / 8$ & ns \\
\hline $\begin{array}{l}\text { Smoking status } \\
\text { (former/current) }\end{array}$ & $0 / 0$ & $7 / 3$ & $6 / 2$ & $15 / 7$ & $12 / 2$ & $10 / 0$ & $<0.001$ \\
\hline Age (years) & $64(62-69)$ & $69(67-70)$ & 70 (68-7I) & $68(63-70)$ & $69(61-72)$ & $64(62-69)$ & ns \\
\hline Height (cm) & 172 (166-I73) & 175 (I64-I78) & 174 (165-189) & I73 (166-I78) & $\mid 74$ (|7|-|78) & $169(156-173)$ & ns \\
\hline Weight (kg) & $66(62-78)$ & $84(65-91)$ & $84(70-93)$ & $74(70-83)$ & $75(68-84)$ & $69(52-74)$ & 0.058 \\
\hline $\mathrm{FEV}_{1}(\% \mathrm{p})$ & $96(89-110)$ & $95(90-100)$ & $92(84-96)$ & $64(56-70)$ & $40(34-42)$ & $26(20-28)$ & $<0.001$ \\
\hline $\mathrm{FEV}_{1}(\mathrm{~L})$ & $2.47(2.40-2.97)$ & $3.02(2.13-3.35)$ & $3.11(2.29-3.47)$ & $1.86(1.53-2.15)$ & $\mathrm{I} .06(0.90-\mathrm{I} .4 \mathrm{I})$ & $0.6 \mathrm{I}(0.53-0.76)$ & $<0.001$ \\
\hline $\mathrm{FEV}_{\mathrm{l}} / \mathrm{FVC}$ & $0.78(0.74-0.8 I)$ & $0.73(0.73-0.78)$ & $0.65(0.60-0.67)$ & $0.55(0.49-0.61)$ & $0.39(0.35-0.42)$ & $0.38(0.33-0.64)$ & $<0.001$ \\
\hline $\mathrm{D}_{\mathrm{L}, \mathrm{CO}}(\% \mathrm{p})$ & 95 (85-99) & 81 (7I-96) & $86(70-104)$ & $72(56-79)$ & $48(28-56)$ & $21(15-25)$ & $<0.001$ \\
\hline $\mathrm{S}_{\text {acin }}\left(\mathrm{L}^{-1}\right)$ & $0.15(0.08-0.21)$ & $0.17(0.05-0.25)$ & $0.17(0.15-0.22)$ & $0.27(0.21-0.43)$ & $0.39(0.35-0.54)$ & $0.44(0.35-0.64)$ & $<0.001$ \\
\hline
\end{tabular}

Note: Data are presented as $\mathrm{n} / \mathrm{n}$ and median (interquartile range).

Abbreviations: \%p, \% of predicted value; GOLD, Global initiative for chronic Obstructive Lung Disease; $\mathrm{D}_{\mathrm{L} \text { co, }}$, diffusion capacity of carbon monoxide over the lung; $F E V_{1}$, forced expiratory volume in I second; FVC, forced vital capacity; ns, not significant; $\mathrm{S}_{\text {acin }}$, ventilation heterogeneity in the acinar airways. 


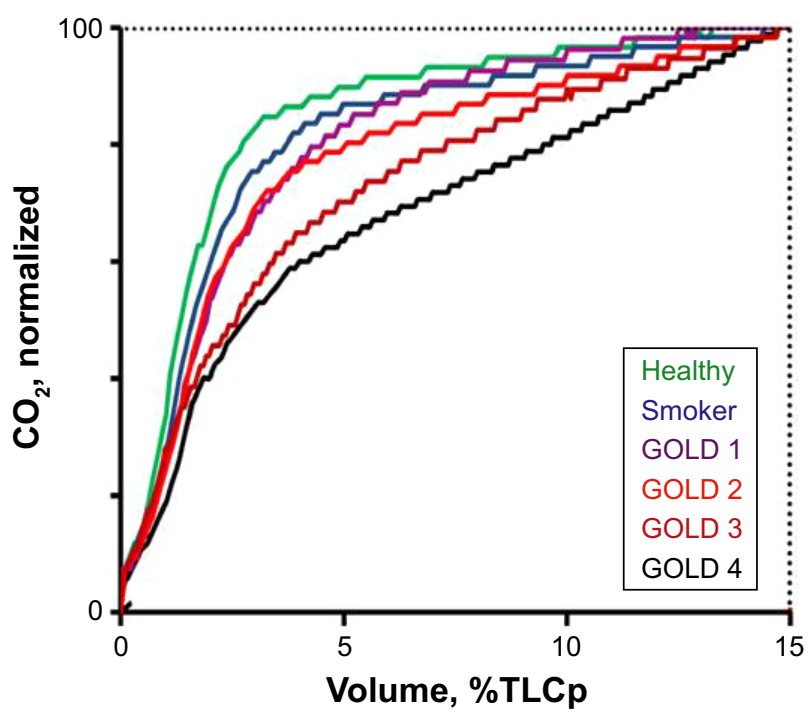

Figure $2 \mathrm{SBT} \mathrm{CO}_{2}$ curves from the subject with median value of EFFi in each group. Note: The analyzed volume is normalized with respect to TLCp, and $\mathrm{CO}_{2}$ is normalized to the value at $15 \%$ TLCp.

Abbreviations: EFFi, Efficiency Index; GOLD, Global initiative for chronic Obstructive Lung Disease; $\mathrm{SBT} \mathrm{CO}_{2}$, single breath test for $\mathrm{CO}_{2}$; TLCp, predicted value for total lung capacity.

comparison between groups (Figure 2) or between results of consecutive follow-up in patients.

Most previous studies are based on limited information from the $\mathrm{SBT} \mathrm{CO}_{2}$ such as slope of Phase II and/or the slope of the alveolar plateau, Phase III. ${ }^{11,19-21}$ Analysis of slope, the derivative of a mathematical function, is inherently sensitive to signal noise. The alveolar plateau is upward convex rather than linear and minor variation in the algorithm may lead to large variation in calculated slope. ${ }^{22}$ EFFi is based on integration of all data over $\mathrm{V}_{\mathrm{AN}}$, a stable, comprehensible mathematical process refractory to noise. Kars et al found that Phase II of the SBT did not provide information sensitive enough for diagnosis of emphysema. ${ }^{10}$ This may reflect that the analysis was limited to a narrow volume interval of the SBT $\mathrm{CO}_{2}$ without relation to predicted lung size.

Low EFFi reflects a combination of: 1) a widened range of alveolar $\mathrm{CO}_{2}$ caused by inhomogeneity of ventilation/ perfusion quotient $(\mathrm{V} / \mathrm{Q})$ among lung compartments; and 2) that compartments with high $\mathrm{V} / \mathrm{Q}$ and low $\mathrm{CO}_{2}$ content during expiration empty sooner than compartments with low V/Q and high $\mathrm{CO}_{2}$ content. ${ }^{23}$ These two phenomena are concurrent in COPD and other obstructive lung diseases. In pulmonary embolism, compartments with high and low $\mathrm{V} / \mathrm{Q}$ empty in synchrony leading to a $\mathrm{SBT}_{\mathrm{CO}_{2}}$ with normal form, but a depressed alveolar plateau. ${ }^{8,18}$

In COPD, the alveolar plateau extrapolated to $15 \%$ of TLC leading to $\mathrm{CO}_{2}$ value indicating the level of arterial
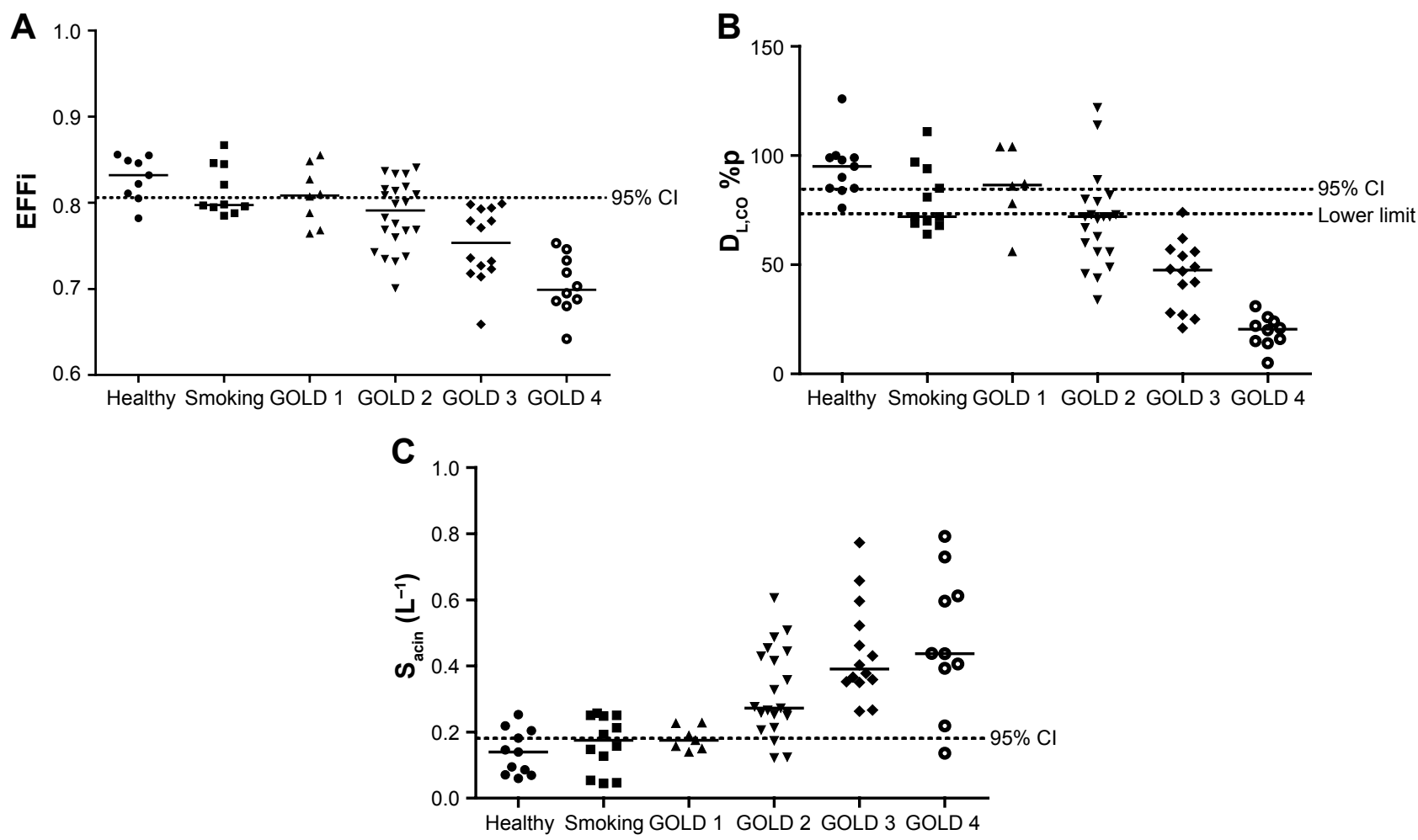

Figure 3 Grading COPD with small airway parameters.

Notes: Grading of COPD severity based on (A) EFFi, (B) $\mathrm{D}_{\mathrm{LCO}} \% \mathrm{p}$ and $(\mathbf{C}) \mathrm{S}_{\text {acin }}$. $95 \%$ confidence interval based on the healthy group is depicted for each parameter. Abbreviations: \%p, \% of predicted value; EFFi, Efficiency Index; GOLD, Global initiative for chronic Obstructive Lung $D_{\text {isease; }} D_{L, c o}$, diffusion capacity of carbon monoxide over the lung; $\mathrm{S}_{\text {acin }}$, ventilation heterogeneity in the acinar airways. 
A
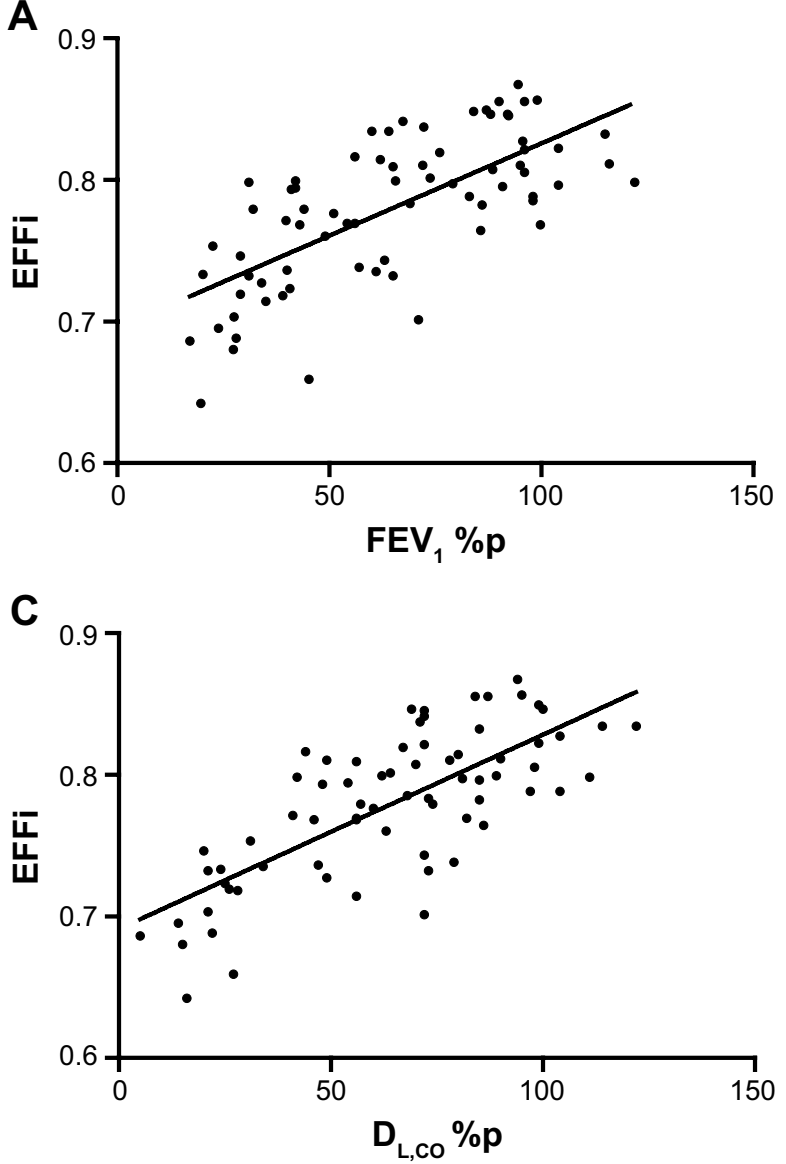

B

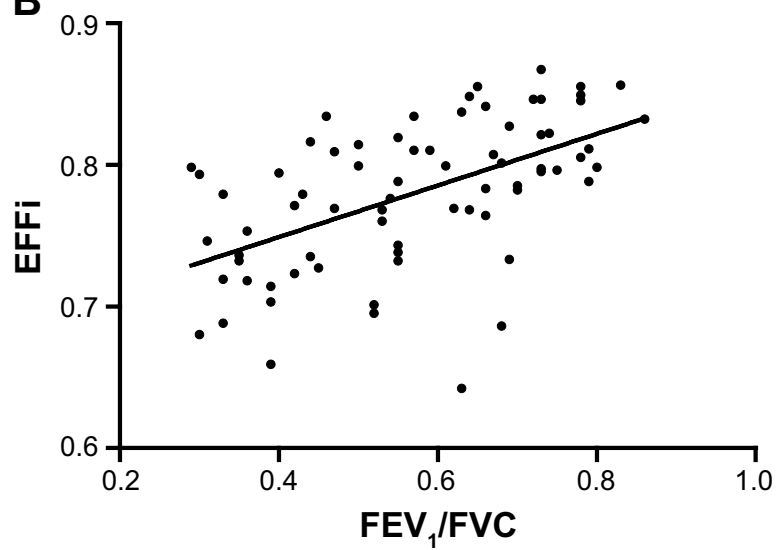

D

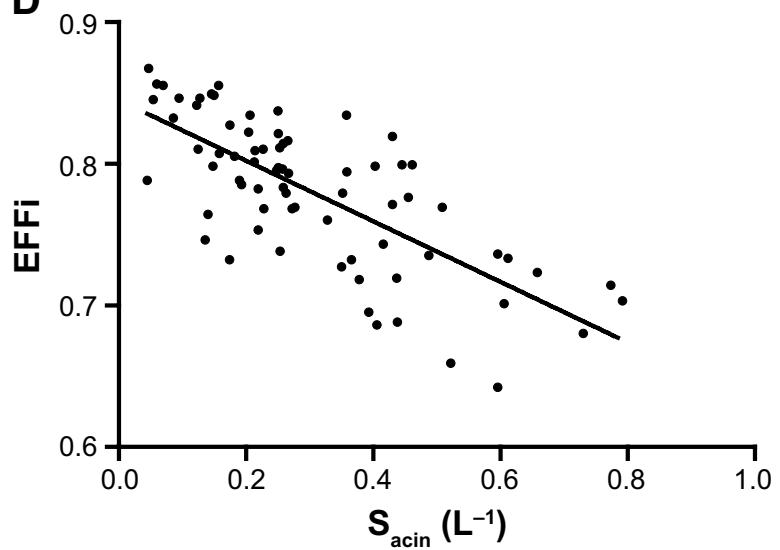

Figure 4 Correlation between EFFi and lung function parameters.

Note: Correlation between EFFi and (A) FEV \% \%, (B) FEV /FVC ratio, (C) $D_{\text {L.CO }}$ and (D) $S_{\text {acin }}$.

Abbreviations: \%p, \% of predicted value; EFFi, Efficiency Index; $\mathrm{D}_{\mathrm{L}, \mathrm{CO}}$, diffusion capacity of carbon monoxide over the lung; $F E V_{1}$, forced expiratory volume in I second; FVC, forced vital capacity; $\mathrm{S}_{\text {acin }}$, ventilation heterogeneity in the acinar airways.

pressure of $\mathrm{CO}_{2}\left(\mathrm{PaCO}_{2}\right) .{ }^{7}$ However, before partial pressure of $\mathrm{CO}_{2}\left(\mathrm{PCO}_{2}\right)$ at expiration of $15 \%$ of TLC is used as an indicator of $\mathrm{PaCO}_{2}$, studies in wider COPD populations are needed.

COPD leads to emphysema, mainly of centrilobular nature. Centrilobular bullae represent high V/Q compartments, while better preserved, more peripheral alveolar structures represent low V/Q compartments. During expiration, gas from central bullae is expired sooner than gas from peripheral alveoli. The two prerequisites for a low EFFi are thereby fulfilled. These compartments are connected in series with one another. Uneven airway obstruction is another pathological feature of COPD. More obstructive lung compartments represent low V/Q compartments which during expiration empty slower than less obstructive, high $\mathrm{V} / \mathrm{Q}$ compartments. These compartments are connected in parallel. VCap does not indicate to what extent serial and parallel compartments contribute to a low EFFi.

A recent analysis emphasizes that ventilatory inefficiency and increased dead space contribute to exertional dyspnea in COPD. ${ }^{24}$ It was concluded that ventilatory inefficiency may progress despite only modest changes in $\mathrm{FEV}_{1}$ and that serial measurements of ventilation over $\mathrm{CO}_{2}$ elimination might prove valuable to track disease progression. This is exactly what EFFi offers in a most simple way. $\mathrm{FEV}_{1}$ (percentage of predicted value) indicates the patient's ventilatory capacity, while EFFi indicates the efficiency of ventilation. $\mathrm{FEV}_{1}$ and EFFi may together explain how physical performance is limited in COPD.

In all GOLD 3 and 4 subjects, EFFi was lower than in healthy subjects. Spirometric criteria for COPD for grade GOLD 1 and 2 have important limitations. ${ }^{25}$ While EFFi allows diagnosis of advanced COPD, further studies are needed to define the usefulness of VCap and EFFi for diagnosis of early COPD. Between all groups, EFFi correlated similarly with $\mathrm{D}_{\mathrm{L}, \mathrm{CO}}$ and $\mathrm{S}_{\text {acin }}$ (Figure 4). The overall agreement between EFFi, $\mathrm{D}_{\mathrm{L}, \mathrm{CO}}$ and $\mathrm{S}_{\text {acin }}$ is explained in that all three measurements reflect uneven ventilation. ${ }^{26}$ $\mathrm{D}_{\mathrm{L}, \mathrm{CO}}$ and $\mathrm{MBW} \mathrm{N}_{2}$ are frequently used as a complement to $\mathrm{FEV}_{1}$ with respect to how the disease affects gas exchange 
and ventilatory inhomogeneity. EFFi would be a simpler alternative that directly indicates how the diseases affect $\mathrm{CO}_{2}$ exchange.

This study is based upon data from previous studies to illustrate physiological aberrations in COPD of varying GOLD grades. ${ }^{14,27,28}$ EFFi was measured in one single breath among the few breaths available before oxygen was administered during the $\mathrm{N}_{2}$ wash out test. The material is small and does not allow consideration of age, which has known effects on V/Q inequality and VCap. ${ }^{12,29}$ Notably, age did not differ between the groups in this study.

This study is suggestive and calls for further studies in larger cohorts before the method can be reliably used for diagnosis of COPD or other obstructive lung diseases. With respect to modelling, it would then be of value to study alternative values of $\mathrm{V}_{\mathrm{AN}}$. In unpublished data from Jonson et al (B Jonson, Lund University, unpublished data, 2000), children and adults with cystic fibrosis point to that an index of the same nature as EFFi may indicate deterioration earlier than spirometry. Therefore, studies of obstructive diseases other than COPD are justified.

\section{Conclusion}

EFFi measures efficiency of tidal $\mathrm{CO}_{2}$ elimination that is limited by inhomogeneity of peripheral lung function. It may be suitable for diagnosis and grading of COPD and may, together with $\mathrm{FEV}_{1}$, explain limitation of physical performance. EFFi may offer an easy, effortless and cost-effective complement to spirometry and might, in some situations, serve as an alternative when spirometry is not possible.

\section{Acknowledgments}

We would like to thank the staff at the Lung Research Unit at Region Skåne Hospital for clinical support. This work was supported by independent research grants from the Swedish Heart and Lung Foundation, Evy and Gunnar Sandberg's Foundation, Crafoord Foundation and Royal Physiographic Society in Lund.

\section{Author contributions}

All authors participated in designing the study and critically revised the manuscript. LJ tested the patients, performed primary analysis, co-wrote the manuscript and performed all statistical calculations. ET, JA and LB helped with collecting data. BJ proposed and performed the calculations and analysis of EFFi and co-wrote the manuscript. All authors approved the final version of the article and are accountable for the accuracy and integrity of the work.

\section{Disclosure}

The authors report no conflicts of interest in this work.

\section{References}

1. Global Initiative for Chronic Obstructive Lung Disease. GOLD 2017 Global Strategy for the Diagnosis, Management and Prevention of COPD. Available from: http://goldcopd.org/gold-2017-global-strategydiagnosis-management-prevention-copd/. Accessed May 8, 2017.

2. Jarenbäck L. Chronic Obstructive Pulmonary Disease - lung physiology and genetic links [thesis]. Lund: Department Clinical Science, Lund, Lund University; 2016.

3. Martinez FD. Early-life origins of chronic obstructive pulmonary disease. N Engl J Med. 2016;375(9):871-878.

4. Woodruff PG, Couper D, Han MK. Symptoms in smokers with preserved pulmonary function. $N$ Engl J Med. 2016;375(9):896-897.

5. Woodruff PG, Barr RG, Bleecker E, et al. Clinical significance of symptoms in smokers with preserved pulmonary function. $N$ Engl J Med. 2016;374(19):1811-1821.

6. Wang S, Gong W, Tian Y. Voluntary pulmonary function screening identifies high rates of undiagnosed asymptomatic chronic obstructive pulmonary disease. Chron Respir Dis. 2016;13(2):137-143.

7. Mannino DM. Does undiagnosed chronic obstructive pulmonary disease matter? Am J Respir Crit Care Med. 2016;194(3):250-252.

8. Eriksson L, Wollmer P, Olsson CG, et al. Diagnosis of pulmonary embolism based upon alveolar dead space analysis. Chest. 1989;96(2):357-362.

9. You B, Peslin R, Duvivier C, Vu VD, Grilliat JP. Expiratory capnography in asthma: evaluation of various shape indices. Eur Respir J. 1994;7(2): 318-323.

10. Kars AH, Goorden G, Stijnen T, Bogaard JM, Verbraak AF, Hilvering C. Does phase 2 of the expiratory $\mathrm{PCO} 2$ versus volume curve have diagnostic value in emphysema patients? Eur Respir J. 1995;8(1):86-92.

11. Ponto S. Kapnovolumetrie als mitarbeitsfreie Diagnostik in der Lungenfunktionsanalyse [Volumetric capnography as a work-free diagnostic in pulmonary function analysis] [thesis]. Schweinfurt: UFL Private Universität im Fürstentum Liechtenstein; 2015. German.

12. Aström E, Niklason L, Drefeldt B, Bajc M, Jonson B. Partitioning of dead space - a method and reference values in the awake human. Eur Respir J. 2000;16(4):659-664.

13. Fletcher R, Jonson B. Deadspace and the single breath test for carbon dioxide during anaesthesia and artificial ventilation. Effects of tidal volume and frequency of respiration. Br J Anaesth. 1984;56(2): 109-119.

14. Jarenbäck L, Ankerst J, Bjermer L, Tufvesson E. Acinar ventilation heterogeneity in COPD relates to diffusion capacity, resistance and reactance. Respir Med. 2016;110:28-33.

15. Crapo RO, Morris AH, Gardner RM. Reference spirometric values using techniques and equipment that meet ATS recommendations. Am Rev Respir Dis. 1981;123(6):659-664.

16. Quanjer PH, Tammeling GJ, Cotes JE, Pedersen OF, Peslin R, Yernault JC. Lung volumes and forced ventilatory flows. Report Working Party Standardization of Lung Function Tests, European Community for Steel and Coal. Official Statement of the European Respiratory Society. Eur Respir J Suppl. 1993;16:5-40.

17. Robinson PD, Latzin P, Verbanck S, et al. Consensus statement for inert gas washout measurement using multiple- and single-breath tests. Eur Respir J. 2013;41(3):507-522.

18. Olsson K, Jonson B, Olsson CG, Wollmer P. Diagnosis of pulmonary embolism by measurement of alveolar dead space. J Intern Med. 1998;244(3):199-207.

19. Veronez L, Pereira MC, da Silva SM, et al. Volumetric capnography for the evaluation of chronic airways diseases. Int J Chron Obstruct Pulmon Dis. 2014;9:983-989.

20. Romero PV, Rodriguez B, de Oliveira D, Blanch L, Manresa F. Volumetric capnography and chronic obstructive pulmonary disease staging. Int J Chron Obstruct Pulmon Dis. 2007;2(3):381-391. 
21. Qi GS, Gu WC, Yang WL, Xi F, Wu H, Liu JM. The ability of volumetric capnography to distinguish between chronic obstructive pulmonary disease patients and normal subjects. Lung. 2014;192(5):661-668.

22. Tusman G, Scandurra A, Böhm SH, Suarez-Sipmann F, Clara F. Model fitting of volumetric capnograms improves calculations of airway dead space and slope of phase III. J Clin Monit Comput. 2009;23(4): 197-206.

23. Fletcher R, Jonson B, Cumming G, Brew J. The concept of deadspace with special reference to the single breath test for carbon dioxide. $\mathrm{BrJ}$ Anaesth. 1981;53(1):77-88.

24. Neder JA, Berton DC, Muller PT, et al. Ventilatory inefficiency and exertional dyspnea in early chronic obstructive pulmonary disease. Ann Am Thorac Soc. 2017;14(Supplement_1):S22-S29.

25. Wollmer P, Engström G. Fixed ratio or lower limit of normal as cutoff value for FEV1/VC: an outcome study. Respir Med. 2013;107(9): 1460-1462.
26. Wagner PD, Dantzker DR, Dueck R, Clausen JL, West JB. Ventilationperfusion inequality in chronic obstructive pulmonary disease. J Clin Invest. 1977;59(2):203-216.

27. Eriksson G, Jarenback L, Peterson S, Ankerst J, Bjermer L, Tufvesson E. A new approach to assess COPD by identifying lung function breakpoints. Int J Chron Obstruct Pulmon Dis. 2015;10:2193-2202.

28. Jarenbäck L, Ankerst J, Bjermer L, Tufvesson E. Flow-volume parameters in COPD related to extended measurements of lung volume, diffusion, and resistance. Pulm Med. 2013;2013:782052.

29. Cardús J, Burgos F, Diaz O, et al. Increase in pulmonary ventilationperfusion inequality with age in healthy individuals. Am J Respir Crit Care Med. 1997;156(2 Pt 1):648-653.

\section{Publish your work in this journal}

The International Journal of COPD is an international, peer-reviewed journal of therapeutics and pharmacology focusing on concise rapid reporting of clinical studies and reviews in COPD. Special focus is given to the pathophysiological processes underlying the disease, intervention programs, patient focused education, and self management protocols.

\section{Dovepress}

This journal is indexed on PubMed Central, MedLine and CAS. The manuscript management system is completely online and includes a very quick and fair peer-review system, which is all easy to use. Visit http://www.dovepress.com/testimonials.php to read real quotes from published authors.

Submit your manuscript here: http://www.dovepress.com/international-journal-of-chronic-obstructive-pulmonary-disease-journal 